\title{
Predominant Factors Affecting Sexual Dysfunction on Patients with Continuous Ambulatory Peritoneal Dialysis
}

\author{
Yuswinda Kusumawardhani $i^{1,3}$ (D) Krisna Yetti $^{2 *}$ (D) I Made Kariasa ${ }^{2}$ (D) \\ ${ }^{1}$ Postgraduate Nursing Program, Faculty of Nursing, Universitas Indonesia, Depok, West Java, Indonesia; ${ }^{2}$ Department of \\ Nursing, Faculty of Nursing, Universitas Indonesia, Depok, West Java, Indonesia; ${ }^{3}$ Department of Nursing, Dr. Kariadi Hospital, \\ Semarang, Indonesia
}

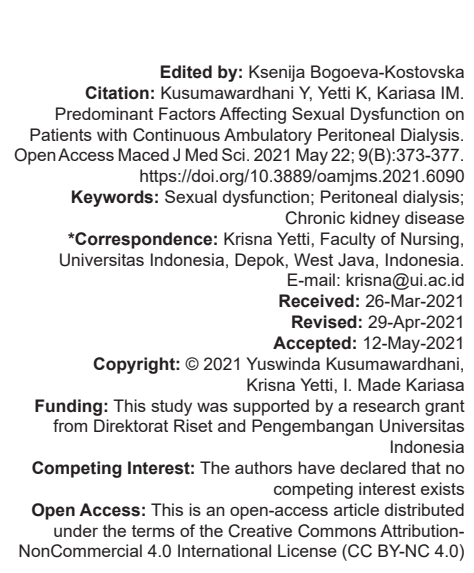

\section{Introduction}

One of the dialysis therapies that patients usually choose besides hemodialysis is continuous ambulatory peritoneal dialysis (CAPD). Glucose is the osmotic agent most often used in commercial peritoneal dialysis fluids. High glucose concentrations in the dialysate are associated with osmotic gradients, ultrafiltration, and withdrawal of fluid retention. On the other hand, excessive glucose absorption from dialysate is likely responsible for lipid abnormalities (dyslipidemia). The prevalence of metabolic syndrome in terminal renal failure patients on peritoneal dialysis is quite common, ranging from $40 \%$ to $60 \%$ [1]. The collection of metabolic disorders can lead to further complications including malnutrition, inflammation, and atherosclerosis as much as $31.4 \%$. The existence of a set of metabolic disorders is likely to affect sexual function. In addition, uremia which is toxic has a direct role that causes testicular damage [2]. Uremia which also spreads throughout the body can damage the peripheral and central nervous system.
Autonomic neuropathy can be a cause of impotence, erectile problems, and reduced sensitivity to sexual stimulation [2].

This supports the data that both male predialysis chronic kidney disease patients and male dialysis patients experience problems with sexual dysfunction [3]. The tendency of an increase in chronic kidney failure at a young age from $29.21 \%$ in 2013 to $30.31 \%$ in 2018 [4] greatly affected the problem of sexuality and is predicted to increase the incidence of sexual dysfunction. Furthermore, in our clinical practice with patients who underwent CAPD, we confronted with men declaring loss of erection in the morning, problem during intercourse, and less intercourses. The problem of sexual dysfunction experienced by men undergoing CAPD is very complex covering five domains of sexual dysfunction and the problem of meeting sexual needs is more frequently complained by male patients than female patients. This is in line with Rosas et al. study showing sexual dysfunction in patients undergoing dialysis (80\% in men vs. $50 \%$ in women) [3], [5]. Hence, we focused on conducting a research study in men undergoing CAPD. 
Sexual dysfunction is a common problem experienced by dialysis patients, but limited studies have addressed this problem in CAPD patients compared to hemodialysis patients. The aims of this study were to describe the sexual dysfunction of male patients who underwent CAPD and to find out the most dominant factor influencing sexual dysfunction.

\section{Methods}

This research is a descriptive analytic study with the cross-sectional approach. This study received ethical approval from the Research Ethics Committee of the Faculty of Nursing, Universitas Indonesia (No. 16/ UN2.F12.D1.2.1/ETIK.FIK.2020). All respondents were given an explanation before the study takes place regarding the purpose of research, research procedures, and benefits if respondents participated in this study. After the respondent understands, then the respondent was given the opportunity to sign an informed consent and then fill out the questionnaire. All authors conceived the idea and plan of the research, then the first author conducted research in consultation with the second author and third author.

This study was conducted on 70 CAPD male patients given a dialysate fluid concentration of $1.5 \%$ and/or 2.5\%, and aged 26-65 years old in Central Java region using purposive sampling by fulfilling the inclusion and exclusion criteria established. Patients suffering from diabetes mellitus before undergoing CAPD, having comorbidities such as heart failure, stroke, or peritonitis, had a history of previous urological surgery, unmarried, depression, and taking antidepressant drugs which were excluded from the study. Determination of sample criteria is very helpful for researchers reduce the bias of the study results. The time duration of patient recruitment was around 13 weeks from February to May in 2020. The Indonesian version of International Index of Erectile Function questionnaire was used to determine the presence of sexual dysfunction. This questionnaire consists of 15 items divided into five domains sexual function male (erectile function 6 items, orgasm function 2 items, sexual desire 2 items, intercourse satisfaction 3 items, and overall satisfaction 2 item). Assessment uses $0-5$ Likert scale, where 0 is not there is activity and 5 is almost always [6]. The measurement result is not dysfunction sexual $>60$ and dysfunction sexual $(\leq 60)$. Fifty-nine patients provided the data on site and filled out the respondent's questionnaire, and the researcher recorded the results of the respondent's laboratory at that time. Eleven other patients filled out an online questionnaire and reported laboratory photos at 1 time which coincided with the time for filling out the questionnaire, due to the policy of limiting activities and visits related to coronavirus disease 2019 .
The data collected were analyzed using SPSS 16.0. The univariate statistical test in this study is presented in the form of frequencies and percentages, and then, the bivariate test used Chi-square test. Multiple logistic regression analysis was used to determine the main determinant factors that influenced sexual dysfunction in men undergoing CAPD.

\section{Results}

A total of 70 male patients using CAPD filled out a questionnaire and recorded the result of laboratory tests. The majority of men who underwent CAPD had sexual dysfunction (Figure 1).

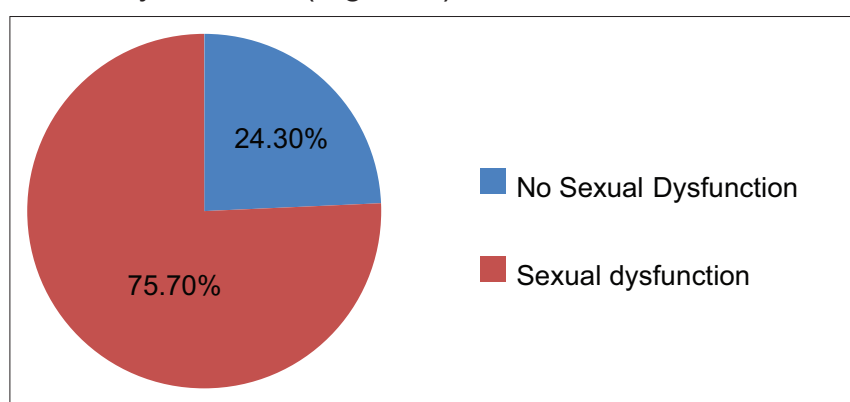

Figure 1: Description of the distribution of sexual dysfunction in male patients of continuous ambulatory peritoneal dialysis

The most of CAPD patients were aged above 46 years, with a long duration of CAPD $<36$ months, urea level $>100 \mathrm{mg} / \mathrm{dL}$, fasting glucose level $<110 \mathrm{mg} /$ $\mathrm{dL}$, triglyceride levels $\leq 150 \mathrm{mg} / \mathrm{dL}$, cholesterol levels $\leq 200 \mathrm{mg} / \mathrm{dL}$, and albumin levels $<3.5 \mathrm{~g} / \mathrm{dl}$ (Table 1).

Table 1: Characteristics of the study patients and incidence of sexual dysfunction

\begin{tabular}{|c|c|c|c|c|c|c|c|}
\hline \multirow{3}{*}{ The factors } & \multicolumn{4}{|c|}{ Sexual dysfunction } & \multirow{2}{*}{\multicolumn{2}{|c|}{ Total }} & \multirow[t]{3}{*}{$p$-value } \\
\hline & \multicolumn{2}{|c|}{$\begin{array}{l}\text { No sexual } \\
\text { dysfunction }\end{array}$} & \multicolumn{2}{|c|}{$\begin{array}{l}\text { Sexual } \\
\text { dysfunction }\end{array}$} & & & \\
\hline & $\mathrm{n}$ & $\%$ & $\mathrm{n}$ & $\%$ & $n$ & $\%$ & \\
\hline Age (years old) & & & & & & & $0.024^{*}$ \\
\hline $26-45$ & 11 & 40.7 & 16 & 59.3 & 27 & 100 & \\
\hline $46-65$ & 6 & 14 & 37 & 86 & 43 & 100 & \\
\hline \multicolumn{8}{|c|}{ Length of time undergoing } \\
\hline \multicolumn{8}{|c|}{ CAPD (months) } \\
\hline$\geq 36$ & 3 & 33.3 & 6 & 66.7 & 9 & 100 & 0.678 \\
\hline \multirow{2}{*}{\multicolumn{8}{|c|}{ Plasma urea (mg/dL) }} \\
\hline & & & & & & & \\
\hline$\leq 100$ & 12 & 40 & 18 & 60 & 30 & 100 & $0.018^{*}$ \\
\hline$>100$ & 5 & 12.5 & 35 & 87.5 & 40 & 100 & \\
\hline \multicolumn{8}{|c|}{ Fasting glucose (mg/dL) } \\
\hline$\leq 110$ & 15 & 32.6 & 31 & 67.4 & 46 & 100 & 0.051 \\
\hline$>110$ & 2 & 8.3 & 22 & 91.7 & 24 & 100 & \\
\hline \multicolumn{8}{|c|}{ Triglycerides (mg/dL) } \\
\hline$\leq 150$ & 14 & 26.4 & 39 & 73.6 & 53 & 100 & 0.536 \\
\hline$>150$ & 3 & 17.6 & 14 & 82.4 & 17 & 100 & \\
\hline \multicolumn{8}{|c|}{ Cholesterol (mg/dL) } \\
\hline$\leq 200$ & 17 & 27 & 46 & 73 & 63 & 100 & 0.183 \\
\hline$>200$ & 0 & 0 & 7 & 100 & 7 & 100 & \\
\hline \multicolumn{8}{|l|}{ Albumin (g/dL) } \\
\hline $3.5-5$ & 13 & 46.4 & 15 & 53.6 & 28 & 100 & $0.001^{*}$ \\
\hline$<3.5$ & 4 & 9.5 & 38 & 90.5 & 42 & 100 & \\
\hline
\end{tabular}

Sexual dysfunction was significantly correlated with age, plasma urea, and albumin. Meanwhile, as factors that had no significant correlation with sexual dysfunction, we found the length of time undergoing CAPD, fasting glucose, triglycerides, and cholesterol 
(Table 1). Variables that have $p>0.25$ can be included in the multivariate modeling. The next stage of multivariate modeling is where the variable that has $p \leq 0.05$ in the bivariate test is a valid variable in the multivariate model. Variables having $p>0.05$ are excluded from the model. Variable expenditure is carried out in stages one by one starting from the variable that has the greatest $p$-value, which is the result of the last modeling shown in Table 2 . The results of the multiple logistic regression modeling showed that respondents who had albumin level $<3.5 \mathrm{~g} / \mathrm{dL}$ had a 9.3 times risk higher of experiencing sexual dysfunction compared with the respondents who had albumin levels of $3.5-5 \mathrm{~g} / \mathrm{dL}$ after age adjustment (95\% Cl: $2.4-36.5)$. Respondents with an age range of 46-65 years old were at risk experiencing sexual dysfunction 5 times higher experiencing sexual dysfunction compared with respondents in the age range of 26-45 years old after being adjusted by albumin variable $(95 \% \mathrm{Cl}$ : 1.3-18.6). The variable that mostly influenced sexual dysfunction was albumin (Table 2).

Table 2: Multivariate logistic regression model for male sexual dysfunction with CAPD

\begin{tabular}{lllll}
\hline Variable & Coefficient B & OR & $95 \% \mathrm{Cl}$ & $\mathrm{p}$-value \\
\hline Age & 1.610 & 5.000 & $1.3-18.6$ & 0.016 \\
Albumin constant & $2.233-0.765$ & $9.324-0.465$ & $2.4-36.5$ & $0.001-0.170$ \\
\hline
\end{tabular}

\section{Discussion}

The results showed that majority of respondents were in the age range of 46-65 years, which is consistent with reports showing that $20-40 \%$ of patients have started CAPD at the age above of 45 years old. In those cases, patients with this age range had difficulty in vascular access, so it was more suitable for them to use CAPD [7]. The results of the analysis in this study showed that there was a significant relationship between age and sexual dysfunction $(p=0.024)$. This finding supported by Antonucci et al. study which showed that terminal kidney failure in patients aged over 50 years led to erectile dysfunction by $61 \%$ and that risk increased to 7.8 after being adjusted for diabetes variables [8]. The aging-related process that leads to sexual dysfunction begins when a man is in his fourth decade, with an estimated $40 \%$ chance of erectile dysfunction and an increase of about $10 \%$ afterward. When about $15 \%$ of corporal smooth muscle cells have decreased, this causes the nerve bundles in the penis to be less sensitive in translating stimuli [9].

Our results showed that majority of respondents had just undergone CAPD for $<36$ months. In this study, no significant relationship was found between the length of undergoing CAPD with male sexual dysfunction $(p=0.678)$. The chronic kidney failure disease shows decreased libido along with the development of kidney disease, remaining low during dialysis, and improvement after transplantation [2]. In kidney transplant recipients, the prevalence is lower compared to those undergoing dialysis both peritoneal dialysis and hemodialysis $(59 \%$ vs. $75 \%$ ) [10].

The results of this study indicate that the majority of respondents who have urea levels $>100 \mathrm{mg} / \mathrm{dL}$ experience sexual dysfunction. In theory, uremia causes histological changes in the testes which decrease the spermatogenic activity and also influences the level of testosterone to be low, whereas testosterone is a hormone that is involved in the mechanism of erectile function by maintaining nitric oxide synthase activity [2]. Low testosterone levels result in increased plasma luteinizing hormone, and follicle stimulating hormone concentrations result in an increase in prolactin levels. Hyperprolactinemia can damage the structure of the testis so that it is associated with infertility, loss of libido, and testosterone deficiency [11]. It is like a complex circle of reciprocal relationships that affect the male sexual function. In line with the theory, the results of this study show that there is a relationship between urea levels and sexual dysfunction $(p=0.018)$. In this study also, the majority of respondents had levels of urea $>100 \mathrm{mg} / \mathrm{dL}$ and were in the age range of 46-65 years, which according to Musch et al., increased age is in line with increasing levels of urea and decreasing the body's ability in urea excretion [12]. One of the roles of the CAPD nurse is to monitor dialysis adequacy and collaborate with medical personnel to achieve dialysis adequacy [13].

Several studies have observed excessive glucose absorption from CAPD dialysate [1]. This contrasts with this study in which the majority of respondents had fasting glucose levels $\leq 110 \mathrm{mg} / \mathrm{dL}$. This may be due to the use of dialysate fluid concentrations and their dosages that have been adjusted to the patient's peritoneal transport membrane type, including low, low average, high average, and consider low glucose exposure through the peritoneal equilibrium test. In this study, no significant relationship was found between fasting glucose levels and sexual dysfunction in male undergoing CAPD.

The results of this study indicate that the majority of respondents had triglycerides levels $\leq 150 \mathrm{mg} / \mathrm{dL}$ and cholesterol $\leq 200 \mathrm{mg} / \mathrm{dL}$. In this study, exposure to glucose was minimal so as to prevent daily high glucose loads which trigger insulin resistance. This insulin resistance can stimulate the synthesis of other liver-derived proteins, including cholesterol-enriched lipoproteins which play a role in the occurrence of dyslipidemia in CAPD patients [14]. In this study, no significant relationship was found between triglycerides levels and cholesterol levels with sexual dysfunction in men undergoing CAPD. In the previous discussion about fasting glucose, most respondents were at levels $\leq 110 \mathrm{mg} / \mathrm{dL}$ indicating good insulin work where free fatty acids resulting 
from the lipolysis process are not released in large quantities from adipose tissue [15].

The majority of respondents in this study had albumin levels $<3.5 \mathrm{~g} / \mathrm{dL}$. Plasma albumin levels are determined by protein intake, albumin synthesis in the liver, and protein loss through urine consequence, an increase in glomerular permeability, or lost during the dialysis process through dialysate [16]. This is reinforced by Mehrotra study that intake and appetite of dialysis peritoneal patients are lower than the dietary intake of hemodialysis patients [17]. Low appetite is associated with abdominal distension due to the large volume of dialysate in intraperitoneal which can cause abnormal electrical activity of the stomach so that the emptying time is slow [16].

In this study, the majority of respondents had levels of urea $>100 \mathrm{mg} / \mathrm{dL}$ which could interfere with liver work. Related research on the association of uremia and hypoalbuminemia in dialysis patients suggests that low serum albumin also reflects a prolonged inflammatory state as well as a marker of nutritional status [18]. Proinflammatory cytokines such as tumor necrosis factor alpha $(T N F-\alpha)$ in uremic patients increase and induce the production of reactive oxygen species (ROS) in monocytes. Monocytes are considered to play a role in micro-end-stage renal disease (ESRD) inflammation, where an increase in TNF- $\alpha$, interleukin-6, and ROS is considered a pathophysiology of uremic syndrome [19]. Systemic inflammation in these ESRD patients will inhibit albumin synthesis [17]. Other nurse roles are adequate nutrition monitoring where the patient is able to consume the right protein diet (amount and type) and prevention of complications such as malnutrition and infection [13].

The results of this study found an association between albumin levels and sexual dysfunction in men undergoing CAPD. Albumin levels were the most dominant factor affecting sexual dysfunction in men undergoing CAPD. A study conducted by Czub on the mechanism of transport of the hormone testosterone with a serum albumin reports that when albumin levels in the blood are low, the molecular breakdown of albumin-testosterone interactions shows the potential for competition between hormones, other metabolites, and drugs to bind to serum albumin. The compounds present disruption in the transportation of blood and testosterone by albumin [20]. As a result, the disruption in testosterone transport has an impact on CAPD male sexual dysfunction despite normal testosterone levels or albumin levels are negatively correlated with erectile dysfunction, where someone with an albumin level $<3.5 \mathrm{~g} / 100 \mathrm{ml}$ has a higher frequency of erectile dysfunction.

We acknowledge the limitations and strengths of this study. In this study, there are a limited number of samples. However, this cross-sectional study can identify that the majority of respondents experienced sexual dysfunction associated with laboratory parameters other than testosterone, which is a laboratory test that is generally used to look at the health dimensions in CAPD patients.

\section{Conclusion}

The high incidence of sexual dysfunction occurs in male patients undergoing CAPD, in which albumin is the most dominant factor affecting. In the future, in this case, the importance of maximizing the role of CAPD nurses in fulfilling dialysis adequacy, adequate nutrition, and prevention of complications.

\section{Acknowledgments}

The researchers would like to express their gratitude to all participants and to all parties who facilitated this study. This study was supported by Hibah PUTI Prosiding 2020, funded by Direktorat Riset and Pengembangan Universitas Indonesia (NKB-3426/ UN2RST.HKP.05002020) with the grant recipient, namely, the second author.

\section{References}

1. Kei LW. Kidney research and clinical practice metabolic syndrome and obesity in peritoneal dialysis. Kidney Res Clin Pract. 2016;35(1):10-4. https://doi.org/10.1016/j.krcp.2015.12.007 PMid:27069852

2. Kirsten J. Sexual dysfunction in chronic kidney disease. Chronic Renal Dis. 2020;27(6):593-608. https://doi.org/10.1016/ b978-0-12-815876-0.00037-1

3. Rosas S, Joffe M, Franklin E, Strom BL, Kotzker W, Brensinger C et al. Prevalence and determinants of erectile dysfunction in hemodialysis patients. Kidney Int. 2001;59(6):2259-66. https:// doi.org/10.1046/j.1523-1755.2001.0590062259.x PMid:11380829

4. Indonesian Renal Registry. $11^{\text {th }}$ Report of Indonesian Renal Registry. Indonesian: Indonesian Renal Registry; 2018.

5. Finkelstein F, Shirani S, Wuerth D, Finkelstein SH. Therapy insight: Sexual dysfunction in patients with chronic kidney disease. Nat Clin Pract Nephrol. 2007;3:200-7. https://doi. org/10.1038/ncpneph0438 PMid:17389889

6. Yudhistra PK, Farizal RM, Mahendrata RA. Validity and reliability of the Indonesian version of the international index of erectile function. J Clin Urol. 2020;1-5. https://doi. org/10.1177/2051415820927819

7. Ploumis SP, Dimitrios GO. Diabetic patients on peritonea dialysis. Wiley Online Lib. 2010;23:191-7. https://doi. org/10.1111/j.1525-139x.2010.00707.x 
8. Antonucci M, Palermo G, Salvatore MR, Bientinesi $R$, Presicce F, Foschi N, et al. Male sexual dysfunction in patients with chronic end-stage renal insufficiency and in renal transplant recipients. Arch Ital Urol Androl. 2015;87(4):299-305. https://doi. org/10.4081/aiua.2015.4.299

\section{PMid:26766802}

9. Ferrini MG, Cadavid-Gonzalez NF, Rajfer J. Aging related erectile dysfunction-potential mechanism to halt or delay its onset. Transl Androl Urol. 2017;6:20-7. https://doi.org/10.21037/ tau.2016.11.18

$$
\text { PMid:28217447 }
$$

10. Mesquita JF, Ramos TF, Mesquita FP, Netto JM, Bastos MG, de Figueriedo AA. Prevalence of erectile dysfunction in chronic renal disease patients on conservative treatment. Clinics (Sao Paulo). 2012;67(2):181-3. https://doi.org/10.6061/clinics/2012(02)15

11. Papadopoulou E, Varouktsi A, Lazaridis A, Boutari C, Doumas M, Papadopoulou E, et al. Erectile dysfunction in chronic kidney disease: From pathophysiology to management. World J Nephrol. 2015;4(3):379-87. https://doi.org/10.5527/wjn. v4.i3.379

PMid:26167462

12. Musch W, Verfaille L, Decaux G. Age related increase in plasma urea and decrease in fractional urea excretion: Clinical application in the syndrome of inappropriate secretion of antidiuretic hormone. Clin J Am Soc Nephrol. 2006;1(5):909-14 https://doi.org/10.2215/cjn.00320106

PMid:17699306

13. Yumi K, Tsutomu I, Hiromichi S. Role of nurses in a continuous ambulatory peritoneal diagnosis outpatient clinic. Karger. 2012;177:64-70. https://doi.org/10.1159/000336937 PMid:22613916

14. Kadiroglu AK, Ustundag S, Kayabashi H, Yilmaz Z, Yildrim Y,
Sen $S$, et al. A comparative study of the effect of icodextrin based peritoneal dialysis and hemodialysis on lipid metabolism. Indian J Nephrol. 2013;23:358-61. https://doi. org/10.4103/0971-4065.116324

PMid:24049273

15. John EH, Arthur CG. Guyton and Hall Textbook of Medical Physiology. Philadelphia, PA: Saunders Elsevier; 2011. p. 961-9.

16. Steven $\mathrm{H}$. Hypoalbuminemia in peritoneal dialysis patients. Adv Perit Dial. 2013;29:55-60.

PMid:24344493

17. Mehrotra R. Nutrional issues in peritoneal dialysis patients: How do they differ from that of patients undergoing hemodialysis? J Ren Nutr. 2013;23(3):237-40. https://doi.org/10.1053/j. jrn.2013.01.031

PMid:23611553

18. Alves CF, Sun J, Qureshi AR, Dai L, Snaedal S, Barany P, et al. The higher mortality associated with low serum albumin is dependent on systemic inflammation in end-stage kidney disease. PLoS One. 2018;13:e0190410. https://doi.org/10.1371/ journal.pone. 0190410

PMid:29298330

19. Bonan NB, Schepers E, Pecoits-Filho R, Dhondt A, Pletinck A, De Somer $F$, et al. Contribution of the uremic milieu to an increased pro-inflammatory monocytic phenotype in chronic kidney disease. Sci Rep. 2019;9:1-11. https://doi.org/10.1038/ s41598-019-46724-5-5

20. Czub MP, Venkataramany BS, Majorek KA, Handing KB, Porebski PJ, Beeram SR, et al. Testosterone meets albuminthe molecular mechanism of sex hormone transport by serum albumins. Chem Sci. 2019;10:1607-18. https://doi.org/10.1039/ c8sc04397c 